\title{
Recovery of Energy Metabolism in Rat Brain after Carbon Monoxide Hypoxia
}

Steven D. Brown and Claude A. Piantadosi

Department of Medicine, Duke University Medical Center, Durham, North Carolina 27710

\begin{abstract}
Carbon monoxide (CO) may inhibit mitochondrial electron transport in the brain and increase the toxic effects of the gas. This hypothesis was investigated in anesthetized rats during CO exposure and recovery at either normobaric or hyperbaric $\mathrm{O}_{2}$ concentrations. During exposure and recovery, we measured the oxidation level of cerebrocortical cytochrome $c$ oxidase by differential spectroscopy and biochemical metabolites known to reflect aerobic energy provision in the brain. $\mathrm{CO}$ exposure $(\mathrm{HbCO}=71 \pm 1 \%)$ significantly decreased blood pressure and cytochrome oxidation level. Cerebral ATP was maintained while lactate/pyruvate, glucose, and succinate rose, and phosphocreatine (PCr) fell, relative to control $(P<0.05)$. Intracellular pH (pHi) calculated from the PCr equilibrium also declined during the exposures. During recovery, $\mathrm{HbCO}$ fell more rapidly at hyperbaric than at normobaric $\mathrm{O}_{2}$ levels, but returned to $10 \%$ or less in both groups by $45 \mathrm{~min}$. Cytochrome oxidation state improved to $80 \%$ of control after 90 min at normobaric $\mathrm{O}_{2}$, but recovered completely after hyperbaric $\mathrm{O}_{2}(P<0.05)$. In normobaric $\mathrm{O}_{2}, \mathrm{PCr}$ and pHi continued to fall for $\mathbf{4 5} \mathrm{min}$ after $\mathrm{CO}$ exposure and did not recover completely by $90 \mathrm{~min}$. $\mathrm{PCr}$ and pHi in animals after hyperbaric $\mathrm{O}_{2}$ improved within 45 min, but also remained below control at $90 \mathrm{~min}$. These data indicate that intracellular uptake of $\mathrm{CO}$ can impair cerebral energy metabolism, despite the elimination of $\mathrm{HbCO}$ from the blood. (J. Clin. Invest. 1992. 89:666-672.) Key words: oxygen • mitochondria $\bullet$ cytochrome $c$-oxidase $\bullet$ respiration $\bullet$ differential spectroscopy
\end{abstract}

\section{Introduction}

The mechanism of $\mathrm{CO}$ toxicity is related to cellular hypoxia and is caused by its tight but reversible binding to hemoglobin (1). This produces functional anemia, increases $\mathrm{O}_{2}$ binding to hemoglobin at low partial pressures of oxygen $\left(\mathrm{PO}_{2}\right)(2)$, and lowers the venous $\mathrm{Po}_{2}$ of the brain despite increases in cerebral blood flow (3). This mechanism deprives cerebral mitochondria of oxygen, but it may not explain all of the clinical consequences (e.g., delayed cerebral manifestations) of toxic exposure to the gas. An extravascular binding site for $\mathrm{CO}$ was suspected as early as 1927 by J. B. S. Haldane (4), and CO binding by cellular hemoproteins, e.g., myoglobin and cytochrome $c$

Address correspondence and reprint requests to Claude A. Piantadosi, M.D., P.O. Box 3315, Duke University Medical Center, Durham, NC 27710.

Received for publication 21 June 1991 and in revised form 24 September 1991 .

J. Clin. Invest.

(c) The American Society for Clinical Investigation, Inc.

$0021-9738 / 92 / 02 / 0666 / 07 \$ 2.00$

Volume 89, February 1992, 666-672 oxidase (E.C. 1.9.3.1), was reported years ago. Cellular CO uptake, however, has been discounted frequently in the pathophysiology of $\mathrm{CO}$ hypoxia because of the high $\mathrm{CO} / \mathrm{O}_{2}$ needed to achieve binding in vitro (1). Over the past few years, intracellular CO uptake by myoglobin in dog muscle (5) and by cytochrome $c$ oxidase in rat brain (6) have been established in vivo, but their roles in the pathophysiology of $\mathrm{CO}$ poisoning are uncertain.

The extent of $\mathrm{CO}$ binding to cytochrome oxidase in the brain is important because of the enzyme's role in mitochondrial electron transport and aerobic production of ATP by the cell (7). Cytochrome oxidase, which reduces $\mathrm{O}_{2}$ to water in a four electron reaction, binds $\mathrm{CO}$ in vitro in any of its four reduced valence states (8). Although the partial pressures of $\mathrm{CO}$ in tissue are quite low, once $\mathrm{CO}$ binds to the oxidase, its release from the enzyme after reoxygenation of the tissue could be slower than its release from $\mathrm{Hb}$, particularly if mitochondrial $\mathrm{Po}_{2}$ is low (9). This chemical behavior would increase the toxic effects of $\mathrm{CO}$ in vivo and could be used to distinguish $\mathrm{CO}$ hypoxia from hypoxic hypoxia. Although many studies have drawn parallels between the two conditions, none have closely examined the recovery of energy metabolism during reoxygenation. During severe exposures, the $\mathrm{PO}_{2}$ at the mitochondrial oxidase could approach zero, and $\mathrm{CO}$ could bind to the ironporphyrin active site without competition from $\mathrm{O}_{2}$ (10). At very low $\mathrm{PO}_{2}$, inhibition of electron transport by $\mathrm{CO}$ and $\mathrm{O}_{2}$ limitation would decrease respiration; however, $\mathrm{CO}$ inhibition of the oxidase could delay restoration of oxidative phosphorylation, as well as impart a greater potential for reoxygenation injury to the brain after $\mathrm{CO}$ hypoxia.

In the present study, we assessed the recovery of cellular energy metabolism, mitochondrial oxidation state, and intracellular $\mathrm{pH}$ in the cerebral cortex of the rat after massive $\mathrm{CO}$ hypoxia. We hypothesized that these metabolic parameters, sensitive both to tissue hypoxia and to inhibition of electron transport by $\mathrm{CO}$, would recover more readily by increasing the extent of alveolar hyperoxia after exposure if $\mathrm{CO}$ binding to cytochrome oxidase significantly increased the toxic effects of the gas. The biochemical data also were compared to results of control studies of cerebrocortical energy metabolism after a similar period of hypoxic hypoxia and recovery.

\section{Methods}

The experiment consisted of two parts. In the first part, cardiopulmonary and cerebrocortical oxidation-reduction (redox) changes were assessed in response to $\mathrm{CO}$ exposure and $90 \mathrm{~min}$ of recovery at normobaric or hyperbaric concentrations of oxygen. In the second part of the experiment, the brains of the animals were frozen rapidly in situ under control conditions, after CO exposure, or after 45 or 90 min of recovery at high inspired $\mathrm{PO}_{2}$ values. Samples of cortical tissue were extracted and then assayed for concentrations of high energy metabolites known to reflect limitations in energy supply.

Animal preparation. Adult male Sprague Dawley rats (Charles River Laboratories, Wilmington, MA) weighing 250-350 g were used 
in the experiments. The animals were anesthetized with intramuscular ketamine $(50 \mathrm{mg} / \mathrm{kg})$ and diazepam $(5 \mathrm{mg} / \mathrm{kg})$, and a tracheotomy was performed. The inferior vena cava was cannulated with polyethylene tubing (PE 50) via the femoral vein. This venous line was used for administration of supplemental anesthetics at one third of the induction dose per hour. One femoral artery was cannulated for continuous blood pressure monitoring (T12AD-R; Spectramed, Oxnard, CA) and intermittent sampling of arterial blood for blood gas and $\mathrm{pH}$ determinations (model $813 \mathrm{pH} / \mathrm{Blood}-\mathrm{Gas}$ Analyzer) and $\mathrm{HbCO}$ measurements (model 482 Co-oximeter, both from Instrumentation Laboratories, Lexington, MA). The animals were placed on a positive pressure rodent respirator (EDCO Scientific, Chapel Hill, NC) after paralysis with tubocurarine chloride $(1.5 \mathrm{mg} / \mathrm{kg})$ to prevent respiratory motion. The animals were ventilated on a control gas mixture of $90 \%$ oxygen $+10 \%$ nitrogen and the ventilator adjusted to provide $\mathrm{a} \mathrm{PaCO}_{2}$ of $35-40$ torr, pH 7.30-7.50, and a $\mathrm{PaO}_{2}$ greater than 250 torr. Animals with inadequate pulmonary gas exchange by these criteria were not studied. The body temperature was monitored with a rectal thermistor and maintained near $37^{\circ} \mathrm{C}$, using a heating pad placed beneath the animal. The head of each animal was immobilized in a stereotaxic device, and a longitudinal scalp incision made to expose the skull. The bone was cleared of periosteum, but left intact so as not to disturb intracranialcirculatory pressure relationships.

Optical monitoring. The absorption characteristics of cerebrocortical cytochrome $c$ oxidase (cytochrome $a, a_{3}$ ) and carboxyhemoglobin in the visible region of the spectrum were monitored continuously through the skull, using a four-wavelength spectrophotometer in the reflectance mode. The technique is the differential method of Chance (11), and the design of the instrument has been described by Jöbsis et al. (12). The spectrophotometer permitted incident light to pass through four tunable monochromators set at $605,620,586$, and $569 \mathrm{~nm}$. The half-bandwidth of the monochromatic output was $3 \mathrm{~nm}$ at 605 , and $620 \mathrm{~nm}$ and $4 \mathrm{~nm}$ at 586 and $569 \mathrm{~nm}$. The light exiting the monochromators alternately passed down a thin fiber optic bundle for illumination of the skull and underlying cerebral cortex. The light was focused with a lens on a spot $\sim 2 \mathrm{~mm}$ wide just beneath the skull. The depth to which light penetrated into the brain was not known precisely; however, most of the signal was probably derived from the first millimeter of cerebral cortex using this optical configuration (13). Diffusely reflected light was collected from the ipsilateral hemisphere using an internally reflecting glass rod coupled to the parietal bone with an optical gel, and shielded from the source by an O-ring. The intensity of the reflected light was measured with a photomultiplier tube (model R928; Hammamatsu, Middlesex, NJ), and the signals for each wavelength were processed through a $\log$ amplifier. Differences in the strengths of the photosignals from reference and sample wavelengths were inscribed on a multichannel recorder (model 560; Gould, Cleveland, $\mathrm{OH})$. Absorption differences at each wavelength in a pair were compensated by adjusting incident light intensity to provide equal photosignals ( $2 \mathrm{~V}$ full scale) under control conditions before logarithmic amplification. The effects of light scattering on the signals were not corrected because the wavelength-dependent scattering function is relatively flat in the $600-\mathrm{nm}$ region, and the sample and reference wavelengths were closely spaced. The changes in the signals during the studies were calibrated to the total labile signal (TLS), ${ }^{1}$ or the difference between the signals in the control state and those obtained after death (14). In some experiments, spectral scans were obtained in the cytochrome $a, a_{3}$ region of the visible spectrum by sweeping wavelengths from 620 to $580 \mathrm{~nm}$ in 3-nm increments.

Changes in the formation and dissolution of $\mathrm{HbCO}$ were followed at the wavelength pair 569 minus $586 \mathrm{~nm}$. This pair of wavelengths represents a triple isosbestic wavelength for $\mathrm{Hb}, \mathrm{HbO}_{2}$, and $\mathrm{HbCO}$, and a double isosbestic wavelength for $\mathrm{Hb}$ and $\mathrm{HbO}_{2}$, respectively. The

1. Abbreviations used in this paper: ATA, atmospheres of absolute pressure; TLS, total labile signal. 569-586-nm difference provides a qualitative estimate of changes in the amount of $\mathrm{HbCO}$ in the circulation (6). The 586-nm signal, used to follows trends in cerebral blood (hemoglobin) volume, is also affected by the formation and dissolution of $\mathrm{HbCO}$.

Changes in the redox state of cytochrome oxidase were measured at 605 minus $620 \mathrm{~nm}$ (14). The optical absorption characteristics of the enzyme complex depend upon its redox state. The reduced minus oxidized difference spectrum of the oxidase shows an alpha absorption maximum in the visible region of the spectrum at $\sim 605 \mathrm{~nm}$, derived primarily from the reduced cytochrome $a$ heme (15). CO binds to the reduced cytochrome $a_{3}$ heme resulting in a decrease in absorption at $605 \mathrm{~nm}$, and a new absorption shoulder at $\sim 590 \mathrm{~nm}$. The absorption decrease at $605 \mathrm{~nm}$ caused by the formation of the cytochrome $a_{3}-\mathrm{CO}$ ligand during $\mathrm{CO}$ hypoxia would cause an underestimate of the reduction level of the enzyme measured at the $605-620$-nm wavelength pair. This underestimate could amount to $15-20 \%$ of the TLS if the entire mitochondrial $a_{3}$ population became reduced and bound $\mathrm{CO}$ during an exposure. In the rat brain, the latter effect may contribute $10 \%$ of the total signal, as measured by comparison of the responses to transient cerebral anoxia to those at death with $\mathrm{CO}$ and anoxia.

Changes in the optical properties of hemoglobin will generate a signal at the 605-620-nm wavelength pair that increases the cytochrome signal by $\sim 15 \%$ between the fully oxygenated condition and complete deoxygenation at death (16). Conversion of $\mathrm{HbO}_{2}$ to $\mathrm{HbCO}$ also increases the OD at 605 and $620 \mathrm{~nm}$ (17). Since the OD ratio of $\mathrm{HbCO}$ to $\mathrm{HbO}_{2}$ is $10 \%$ greater at 620 than at $605 \mathrm{~nm}$, formation of $\mathrm{HbCO}$ from $\mathrm{HbO}_{2}$ will appear as a reduction response of cytochrome oxidase by $\sim 10 \%$ of the change in the hemoglobin signal (17). At $70 \%$ $\mathrm{HbCO}$, as produced in this study, $\mathrm{HbCO}$ formation will increase the cytochrome reduction signal by about $1 \%(15 \% \times 0.1 \times 0.7)$.

Metabolite assays. The brains of control and CO-exposed animals were frozen with liquid nitrogen $\left(\mathrm{N}_{2}\right)$ in situ at different times during the experiments, as performed previously in our laboratory (18). This harvesting procedure was adapted from the funnel freezing method of Ponten et al. (19). During the procedure, the freezing front passed through the brain cortex in 3-5 s while cardiac output sustained cerebral blood flow and tissue oxygenation. This process was designed to minimize autolytic degradation of high energy phosphate metabolites. After freezing the brain for $5 \mathrm{~min}$ in situ, the head was immersed in liquid $\mathrm{N}_{2}$ for another $5 \mathrm{~min}$. The head was then removed, the skull was chiseled away under constant irrigation with $\mathrm{N}_{2}$, and the brain was stored en bloc at $-80^{\circ} \mathrm{C}$ until assayed a few days later. Just before assay, the temperature of the frozen brains was allowed to rise to $-20^{\circ} \mathrm{C}$ in a cold room to facilitate dissection of thin samples of parietal cortex from the areas of optical monitoring. Cortical samples of $\sim 100 \mathrm{mg}$ were weighed and transferred immediately to homogenizer tubes containing $0.1 \mathrm{~N} \mathrm{HCl}$ in methanol at $-20^{\circ} \mathrm{C}$. The cortical tissues were extracted using the method of Folbergrova et al. (20), and the supernatant fractions were neutralized to $\mathrm{pH}$ 7.0.

Aliquots of the supernatants were assayed in duplicate for concentrations of phosphocreatine $(\mathrm{PCr})$, creatine $(\mathrm{Cr})$, adenosine triphosphate (ATP), adenosine diphosphate (ADP), lactic acid (L), pyruvic acid $(P)$, and glucose $(G)$ on a fluorometer (Turner model 112) according to the methods of Lowry and Passoneau (21). Succinic acid concentration was determined fluorometrically using a modification of the spectrophotometric method of Bergmeyer (22). In this procedure, ITP was used to produce succinyl $\mathrm{CoA}$ from succinate, and Coenzyme $A$ in the presence of succinyl thiokinase (E.C. 6.2.1.4). IDP was then rephosphorylated to ITP by phosphoenolpyruvate in the presence of pyruvate kinase (E.C. 2.7.1.40). The pyruvate product was assayed by measuring the disappearance of NADH fluorescence in the lactate dehydrogenase (E.C. 1.1.1.28) reaction. Standard solutions of metabolites were verified spectrophotometrically, and aliquots of the standards were analyzed fluorometrically to obtain standard curves for each batch of samples. All chemicals, enzymes and co-factors were obtained from Sigma Chemical Co. (St. Louis, MO).

Carbon monoxide and oxygen exposures. The exposures to carbon monoxide and oxygen were performed in a hyperbaric chamber using 
commercially mixed gases as reported previously (6). The spectrophotometer was installed in the chamber, and the electrical cables from the photodetector to the amplifier system were passed directly through the steel hull via epoxy-potted penetrations. All of the animals were exposed first to $90 \% \mathrm{O}_{2}+10 \% \mathrm{~N}_{2}$ for assessment of pulmonary gas exchange as noted above. After this baseline period, animals were exposed to either $12 \% \mathrm{O}_{2}$ balance $\mathrm{N}_{2}$, or to $1 \% \mathrm{CO}$ in $90 \% \mathrm{O}_{2}$ (balance $\mathrm{N}_{2}$ ) for $15 \mathrm{~min}$. These hypoxic exposures were followed by recovery on the control gas mixture $\left(90 \% \mathrm{O}_{2}+10 \% \mathrm{~N}_{2}\right)$ at either $1.0 \mathrm{~atm}$ or $2.5 \mathrm{~atm}$ of absolute pressure (ATA) for 45 to $90 \mathrm{~min}$. In the first series of CO exposures, continuous optical monitoring was performed to observe the cerebrocortical redox responses to hypoxia and $90 \mathrm{~min}$ of recovery. These animals were killed after the experiments with intravenous $\mathrm{KCl}$ to obtain a TLS for the cerebral redox responses. In the second series of exposures, brains were frozen in 6 to 10 animals in each of six experimental groups according to the profiles outlined in Table I. Control samples of cortical tissue also were obtained from three groups of animals exposed to profiles indicated in Table I.

Calculation of intracellular $\mathrm{pH}(\mathrm{pHi})$. The intracellular $\mathrm{pH}(\mathrm{pHi})$ was estimated from the creatine phosphokinase (E.C. 2.7.3.2) reaction:

$\left[\mathrm{ADP}^{4-}\right]+[\mathrm{PCr}]+\left[\mathrm{H}^{+}\right] \stackrel{K_{\mathrm{CPK}}}{\rightleftarrows}\left[\mathrm{ATP}^{3-}\right]+[\mathrm{Cr}]$

Assuming equilibrium of the reaction, use of the expression:

$K_{\mathrm{CPK}}=[\mathrm{ATP}][\mathrm{Cr}] /[\mathrm{ADP}][\mathrm{PCr}]\left[\mathrm{H}^{+}\right]$

and a $K_{\mathrm{CPK}}$ of $0.074 \times 10^{9} \mathrm{M}^{-1}(23)$, an estimate of the hydrogen ion $\left[\mathrm{H}^{+}\right]$concentration at the time of freezing was obtained. This calculation assumed stability of the $K_{\mathrm{CPK}}$, intracellular $\left[\mathrm{Mg}^{++}\right]$, and the adenylate kinase equilibrium. It also neglected any compartmentation of energy metabolites in the cell.

Table I. Exposure Profiles for Brain Metabolite Assays

\begin{tabular}{llll}
\hline Group & Exposure conditions & Time & $\begin{array}{c}\text { Freezing } \\
\text { conditions }\end{array}$ \\
\hline & $\min$
\end{tabular}

Experimental
1

2

3

6

Control

$1 \mathrm{C}$

$90 \% \mathrm{O}_{2}+10 \% \mathrm{~N}_{2}$

$90 \% \mathrm{O}_{2}+10 \% \mathrm{~N}_{2}$

$12 \% \mathrm{O}_{2}+88 \% \mathrm{~N}_{2}$

$3 C$
$90 \% \mathrm{O}_{2}+10 \% \mathrm{~N}_{2}$

$90 \% \mathrm{O}_{2}+10 \% \mathrm{~N}_{2}$

$90 \% \mathrm{O}_{2}+1 \% \mathrm{CO}$

$90 \% \mathrm{O}_{2}+10 \% \mathrm{~N}_{2}$

$90 \% \mathrm{O}_{2}+1 \% \mathrm{CO}$

$90 \% \mathrm{O}_{2}+10 \% \mathrm{~N}_{2}$

$90 \% \mathrm{O}_{2}+10 \% \mathrm{~N}_{2}$

$90 \% \mathrm{O}_{2}+1 \% \mathrm{CO}$

$90 \% \mathrm{O}_{2}+10 \% \mathrm{~N}_{2}$

$90 \% \mathrm{O}_{2}+10 \% \mathrm{~N}_{2}$

$90 \% \mathrm{O}_{2}+1 \% \mathrm{CO}$

$90 \% \mathrm{O}_{2}+10 \% \mathrm{~N}_{2}$ (2.5 ATA)

$90 \% \mathrm{O}_{2}+10 \% \mathrm{~N}_{2}$

\% $\mathrm{O}_{2}+1 \% \mathrm{CO}$

$90 \% \mathrm{O}_{2}+10 \% \mathrm{~N}_{2}$ (2.5 ATA)

$90 \% \mathrm{O}_{2}+10 \% \mathrm{~N}_{2}$
$12 \% \mathrm{O}_{2}+88 \% \mathrm{~N}_{2}$

$90 \% \mathrm{O}_{2}+10 \% \mathrm{~N}_{2}$
$\mathrm{X}$

$\mathbf{X}$

$\mathbf{X}$

$\mathrm{X}$

$\mathbf{X}$

$\mathbf{X}$

$\mathrm{X}$

$\mathbf{X}$

$\mathbf{X}$
Statistical methods. All grouped data were expressed as mean and SEM. Statistical significance was determined by one-way ANOVA and the Scheffe $F$-test, using a commercially available software package (StatView 512; Brain Power Inc., Calabasas, CA). A value of $P<0.05$ was accepted as significant.

\section{Results}

Anesthetized rats exposed to $\mathrm{CO}$ or to alveolar hypoxia showed the expected decreases in arterial blood pressure and $\mathrm{O}_{2}$ content. The $\mathrm{HbCO}$ level in $\mathrm{CO}$-exposed rats reached a plateau near 70\% in 5-7 min. The cerebrocortical cytochrome oxidation level fell gradually during $C O$ exposure to $43 \pm 6 \%$ of control. A similar oxidation level of $45 \pm 7 \%$ was achieved in the first few minutes of the 15 -min exposures to $12 \% \mathrm{O}_{2}$. These cytochrome responses, when corrected for the opposing effects of $\mathrm{Hb}$ and $\mathrm{CO}$ on the spectrum of cytochrome oxidase (see Methods), suggest that hypoxemia produced an oxidation level of about $50 \%$, while $\mathrm{CO}$ exposure produced an oxidation level of about $40 \%$ of control. These results provided a rationale for selecting $12 \% \mathrm{O}_{2}$ to determine the reversibility of the changes in cerebral high energy and carbohydrate metabolites produced by hypoxemia in our animal model.

After the $\mathrm{CO}$ exposures, the $\mathrm{HbCO}$ levels in both of the $\mathrm{O}_{2}$ treatment groups approached normal within $90 \mathrm{~min}$; however, the oxidation state of cytochrome oxidase at 1.0 ATA recovered only to $\sim 80 \%$ of its initial value, and the enzyme remained more reduced for at least $90 \mathrm{~min}$ after reoxygenation of the brain. In preliminary experiments, some of the animals subsequently showed gradual reoxidation of the enzyme and others died after a few hours. The oxidation state of the enzyme after exposure to $12 \% \mathrm{O}_{2}$ recovered rapidly to its control value and remained stable for at least two hours thereafter (data not shown). The oxidation level of the enzyme after $\mathrm{CO}$ exposure could be restored to its preexposure baseline within $10 \mathrm{~min}$ by the administration of $90 \% \mathrm{O}_{2}$ at 2.5 ATA. Fig. $1 \mathrm{~A}$ compares the cerebrocortical responses of cytochrome oxidase to $\mathrm{CO}$ and recovery in these two groups of $\mathrm{O}_{2}$-treated animals. The figure demonstrates both failure of the cytochrome $a, a_{3}$ oxidation state to return to control after $90 \mathrm{~min}$ at $1.0 \mathrm{ATA}$, and the return of oxidation state to near normal within $10 \mathrm{~min}$ in the animals treated at 2.5 ATA. These findings were influenced quantitatively by changes in $\mathrm{HbCO}$ and blood volume, but the 569-586-nm signals in both groups returned gradually towards baseline after the $\mathrm{CO}$ exposures. Of note, both groups of animals showed similar declines in blood pressure with the $\mathrm{CO}$ exposures; however, the group treated at 2.5 ATA had a better recovery of the blood pressure (Fig. $1 B$ ).

Fig. 2 shows the difference spectrum of the brain cortex after $45 \mathrm{~min}$ of normobaric recovery vs. an additional $15 \mathrm{~min}$ of hyperbaric recovery. For these experiments, brain spectra at 1.0 ATA were obtained $45 \mathrm{~min}$ after the $\mathrm{CO}$ exposures when the $\mathrm{HbCO}$ level had declined almost to normal. Chamber pressure then was increased to 2.5 ATA over $5 \mathrm{~min}$ and the scans were repeated after $15 \mathrm{~min}$. After subtraction of the 2.5 ATA from the 1.0 ATA scan and linear correction of the baseline, the difference spectrum revealed the alpha band of reduced cytochrome $a, a_{3}$ at $605 \mathrm{~nm}$, and a prominent CO- $a_{3}$ absorption band at 590-596 $\mathrm{nm}$. The maximum OD of this CO- $a_{3}$ band was $10-15 \%$ of the TLS at $605-620 \mathrm{~nm}$. This result indicated that the higher $\mathrm{PO}_{2}$ reoxidized a small fraction of the enzyme in the brain that had remained inhibited after the $\mathrm{CO}$ exposure. 

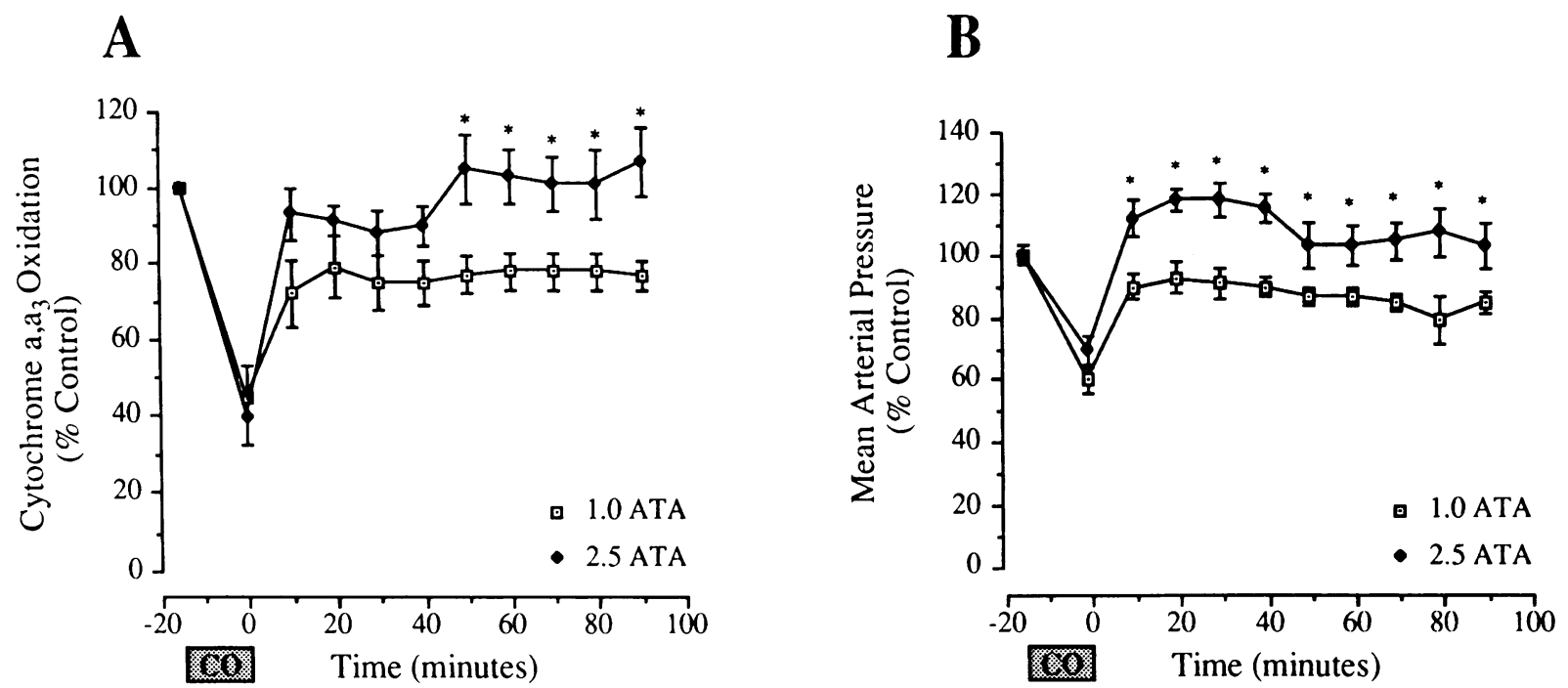

Figure 1. (A) Changes in cerebral cytochrome $a, a_{3}$ oxidation state during and after $\mathrm{CO}$ hypoxia. Reflectance spectroscopy was used to monitor the oxidation state of cytochrome $a, a_{3}$ at 605 minus $620 \mathrm{~nm}$ in the brain cortex of anesthetized rats. $\mathrm{CO}$ exposures were $1.0 \% \mathrm{CO}$ in $90 \% \mathrm{O}_{2}($ balance $\mathrm{N}_{2}$ ) for 15 min followed by 90 min of recovery on $90 \% \mathrm{O}_{2}$ at normobaric $(1.0 \mathrm{ATA}, n=7)$ or hyperbaric $(2.5 \mathrm{ATA}, n=8)$ conditions. Values are mean \pm SEM. Stars indicate significant differences $(P<0.05)$ in recovery responses between the two groups. Peak HbCO levels were $\sim 70 \%$ in both groups of animals. $(B)$ Arterial blood pressure responses to $C O$ hypoxia and recovery. The figure illustrates the extent of decline in blood pressure during $\mathrm{CO}$ hypoxia and a small but significant difference in the mean arterial blood pressure after $\mathrm{CO}$ hypoxia between the two groups of rats in $A$. An augmented response after $\mathrm{CO}$ hypoxia was present in the 2.5 ATA group but not in animals treated at 1.0 ATA. This difference in response may be related to the vasodilator effect of $\mathrm{CO}$, to the vasoconstrictor response to oxygen, or both. All values are mean \pm SEM.

The physiological responses of the rats in the freezing protocols to $\mathrm{CO}$ exposure and hyperoxic recovery at either 1.0 or 2.5 ATA are compared in Tables II and III. The tables indicate that the responses of these groups of animals differed from the animals in the optical studies only by the lack of a difference in blood pressure at the time of brain harvesting between the two $\mathrm{O}_{2}$ groups. The $\mathrm{O}_{2}$ treatment data indicated a slower rate of elimination of $\mathrm{HbCO}$ at $1.0 \mathrm{ATA}$ as expected. After $90 \mathrm{~min}$, however, the $\mathrm{HbCO}$ values had returned to near control levels in both $\mathrm{O}_{2}$ treatment groups. The arterial $\mathrm{O}_{2}$ content values also recovered equally after both types of $\mathrm{O}_{2}$ treatments.

$\mathrm{CO}$ exposure profoundly altered the concentrations of high energy compounds and carbohydrate intermediates in the rat brain cortex. These cortical changes included decreases in the concentration of $\mathrm{PCr}$, and increases in the concentrations of creatine, glucose, lactate, pyruvate and succinate. The ATP and ADP concentrations in the cortex were unaffected by this brief period of acute $\mathrm{CO}$ hypoxia. Similar changes in the metabolite profiles were found in the brain cortex of control animals exposed to $12 \% \mathrm{O}_{2}$ for $15 \mathrm{~min}$ as shown in Table II. Table II also indicates that the changes in energy metabolites after hypoxic hypoxia recovered to near control values within $45 \mathrm{~min}$ of reoxygenation.

Differences in the recovery of brain energy metabolites after $\mathrm{CO}$ hypoxia with the two $\mathrm{O}_{2}$ treatment regimes are presented in Table III. In contrast to hypoxic hypoxia, the metabolic profiles after $\mathrm{CO}$ hypoxia continued to deteriorate for at least $45 \mathrm{~min}$ after the exposure in animals treated on $\mathrm{O}_{2}$ at 1.0 ATA. Treatment at 2.5 ATA, however, promptly improved the energy metabolites after $45 \mathrm{~min}$. The $\mathrm{L} / \mathrm{P}$ ratio remained elevated after $\mathrm{CO}$ hypoxia in all $\mathrm{O}_{2}$ treated groups, due to continued glycolysis and/or a slow rate of clearance of lactate built up during $\mathrm{CO}$ exposure. The glucose and succinate concentrations in the brain continued to rise for $45 \mathrm{~min}$ after the $\mathrm{CO}$ exposure in the 1.0 ATA treatment group, and were significantly higher than the values in the 2.5 ATA group at $45 \min (P<0.05)$. These intermediates, however, recovered after $90 \mathrm{~min}$ of reoxygenation to approximately the same degree in both $\mathrm{O}_{2}$ protocols.

Changes in the cerebrocortical concentrations of $\mathrm{PCr}$ and creatine in response to $\mathrm{CO}$ exposure and recovery also are shown in Table III. The pattern of responses indicates depletion of $\mathrm{PCr}$ during, and $45 \mathrm{~min}$ after, $\mathrm{CO}$ hypoxia in the normobaric groups. There was a small decline in the ATP concentration after $45 \mathrm{~min}$ of reoxygenation in the animals treated with normobaric $\mathrm{O}_{2}$; however, the difference from the control value was not statistically significant. For some reason, the creatine values remained slightly elevated in the $45-\mathrm{min} 2.5$ ATA $\mathrm{O}_{2}$ and the 90 -min post hyperbaric $\mathrm{O}_{2}$ treated groups, although the total creatine $(\mathrm{PCr}+\mathrm{Cr})$ pool size did not differ significantly from control in any of the $\mathrm{CO}$ exposure and treatment groups.

The results of the intracellular $\mathrm{pH}$ calculations for the animals exposed to $\mathrm{CO}$ are provided in Fig. 3. Fig. 3 indicates that the pHi declined significantly during the $\mathrm{CO}$ exposures, and continued to fall during the first $45 \mathrm{~min}$ of recovery on $\mathrm{O}_{2}$ at 1.0 ATA. Oxygen treatment at $2.5 \mathrm{ATA}$, however, returned $\mathrm{pHi}$ towards normal within the first $45 \mathrm{~min}$ of reoxygenation. The $\mathrm{pHi}$ in the 2.5 ATA group was significantly higher than in the 1.0 ATA group at $45 \mathrm{~min}$ of recovery $(P<0.05)$. By $90 \mathrm{~min}$, $\mathrm{pHi}$ in the normobaric treatment group also had improved towards normal, but it had not recovered completely. The pHi in the 2.5 ATA treatment group was improved after $45 \mathrm{~min}$ and largely restored by $90 \mathrm{~min}$; however, the difference be- 


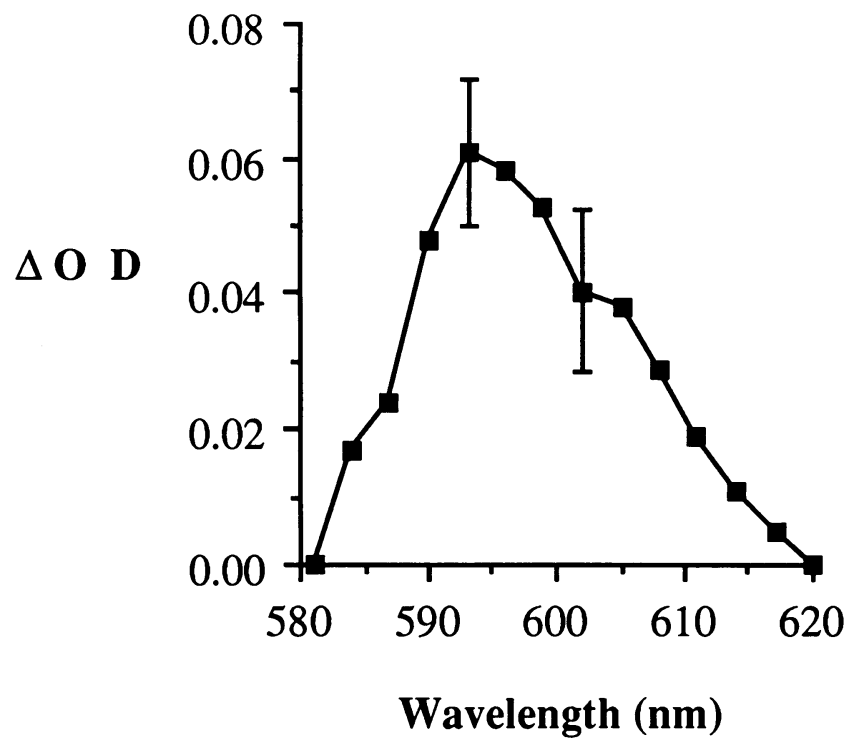

Figure 2. Reflectance difference spectrum of rat brain cortex after $\mathrm{CO}$ hypoxia. Spectra were obtained in four rats by scanning the wavelength region between 620 and $580 \mathrm{~nm}$ in $3 \mathrm{~nm}$ increments under two conditions. The first brain spectrum was recorded with the animal breathing $\mathrm{O}_{2}$ at normobaric conditions beginning $45 \mathrm{~min}$ after $\mathrm{CO}$ exposure as described in Fig. 1. The mean $\mathrm{HbCO}$ level at the time of the first scan was $10.8 \pm 1.2 \%$ in the four experiments. The second spectrum, obtained $15 \mathrm{~min}$ after increasing the atmospheric pressure to 2.5 ATA, was subtracted from the first to obtain a reduced minus oxidized difference spectrum. The spectrum shown is the composite of all four experiments obtained by averaging the absorption values at each wavelength. The standard error bans shown are representative of the variation at all wavelengths. The difference spectrum shows an absorption maximum at $593 \mathrm{~nm}$ characteristic of the absorption band of the cytochrome $a_{3}$-CO ligand and an absorption shoulder at $605 \mathrm{~nm}$ identified with the reduced heme of cytochrome $a$. $\Delta \mathrm{OD}$, change in optical density.

tween the two treatment groups after 90 min of recovery was not statistically significant, possibly due to almost complete restoration of energy metabolism after 90 min of oxygen.

\section{Discussion}

These results raise several novel and potentially important concepts about the pathogenesis of $\mathrm{CO}$ toxicity in the brain. The changes in brain energy metabolites in this study during $\mathrm{CO}$ hypoxia are consistent with previous findings in the rat (24); however, the energy metabolite profiles and spectroscopic data indicate that prolonged intracellular hypoxia and acidosis may follow relatively brief periods of severe $\mathrm{CO}$ hypoxia. After $\mathrm{CO}$ exposure, the mitochondrial oxidation state and metabolite responses indicate that aerobic energy production in the brain cortex was still impaired after nearly complete clearance of $\mathrm{HbCO}$ from the blood, despite administration of elevated $\mathrm{O}_{2}$ concentrations.

One important metabolic consequence of cerebral hypoxia is the decline in the oxidation level of cytochrome oxidase as a function of $\mathrm{Po}_{2}(12,25)$. This in vivo characteristic of the enzyme in the brain, and the effects of $\mathrm{CO}$ on brain mitochondria in vivo in the absence and presence of $\mathrm{Hb}$ circulation $(18,6)$,
Table II. Brain Metabolite Concentrations after CO Hypoxia or Hypoxic Hypoxia*

\begin{tabular}{lcccc}
\hline Variable & Control & CO hypoxia & $12 \% \mathrm{O}_{2}$ hypoxia & $12 \% \mathrm{O}_{2}$ recovery \\
\hline$n$ & 6 & 10 & 6 & 6 \\
$\mathrm{MAP}$ & $113 \pm 7$ & $64 \pm 6^{\ddagger}$ & $48 \pm 12^{*}$ & $117 \pm 5$ \\
$\mathrm{Hb}$ & $14.2 \pm 0.3$ & $10.0 \pm 0.6^{\ddagger}$ & $11.7 \pm 0.4^{*}$ & $12.5 \pm 0.4$ \\
$\mathrm{CaO}_{2}$ & $19.9 \pm 0.4$ & $4.9 \pm 0.2^{\ddagger}$ & $9.6 \pm 0.8^{*}$ & $17.1 \pm 0.5$ \\
$\mathrm{HbCO}$ & $2.3 \pm 0.2$ & $71.4 \pm 0.5^{\ddagger}$ & $2.4 \pm 0.2$ & $2.1 \pm 0.1$ \\
$\mathrm{PaO}_{2}$ & $314 \pm 17$ & $326 \pm 28$ & $40 \pm 3^{*}$ & $394 \pm 10$ \\
$\mathrm{PaCO}_{2}$ & $40.4 \pm 1.1$ & $32.8 \pm 1.2^{\ddagger}$ & $30.2 \pm 2.0^{*}$ & $36.3 \pm 4.9$ \\
$\mathrm{pHa}$ & $7.35 \pm 0.02$ & $7.35 \pm 0.02$ & $7.44 \pm 0.04^{*}$ & $7.45 \pm 0.04^{*}$ \\
$\mathrm{ATP}$ & $2.55 \pm 0.07$ & $2.52 \pm 0.07$ & $2.21 \pm 0.19$ & $2.46 \pm 0.02$ \\
$\mathrm{ADP}$ & $0.42 \pm 0.07$ & $0.39 \pm 0.06$ & $0.62 \pm 0.04^{*}$ & $0.18 \pm 0.03^{*}$ \\
$\mathrm{PCr}$ & $3.52 \pm 0.20$ & $1.87 \pm 0.28^{\ddagger}$ & $1.48 \pm 0.22^{*}$ & $2.66 \pm 0.17^{*}$ \\
$\mathrm{Cr}$ & $4.21 \pm 0.30$ & $7.32 \pm 0.31^{\ddagger}$ & $7.85 \pm 0.15^{*}$ & $5.49 \pm 0.14^{*}$ \\
Succinate & $0.33 \pm 0.03$ & $1.22 \pm 0.15^{\ddagger}$ & $1.04 \pm 0.26^{*}$ & $0.53 \pm 0.03$ \\
Glucose & $2.01 \pm 0.28$ & $2.94 \pm 0.19^{\ddagger}$ & $4.61 \pm 0.20^{*}$ & $3.13 \pm 0.48$ \\
Lactate & $0.89 \pm 0.10$ & $3.96 \pm 0.67^{\ddagger}$ & $6.04 \pm 0.65^{\ddagger}$ & $2.26 \pm 0.16^{*}$ \\
Pyruvate & $0.11 \pm 0.01$ & $0.19 \pm 0.03^{\ddagger}$ & $0.19 \pm 0.02^{\ddagger}$ & $0.17 \pm 0.01^{*}$ \\
L/P & $8.0 \pm 1.1$ & $20.6 \pm 1.8^{\ddagger}$ & $31.5 \pm 4.5^{\ddagger}$ & $13.1 \pm 1.0^{*}$
\end{tabular}

\footnotetext{
${ }^{*}$ Hypoxic periods were $15 \mathrm{~min}$ in duration. The recovery period after hypoxic hypoxia was $45 \mathrm{~min}$ at $\mathrm{FIO}_{2}=0.90$. All values are mean $\pm \mathrm{SE}$. MAP, mean arterial pressure (mmHg); $\mathrm{Hb}$, hemoglobin concentration (g/dl); $\mathrm{CaO}_{2}$, arterial oxygen content $\left(\mathrm{mlO}_{2} / \mathrm{dl}\right) ; \mathrm{HbCO}$, carboxyhemoglobin (\%). Other abbreviations are defined in the text. ${ }^{\ddagger}$ Physiologic variables and metabolite concentrations that are significantly different from control $(P<0.05)$. Metabolite concentrations expressed as micromoles per gram wet weight.
}

suggest the hypothesis that $\mathrm{CO}$ not equilibrated with $\mathrm{Hb}$ during CO hypoxia can inhibit ATP production by binding to reduced cytochrome $c$ oxidase. A role for $\mathrm{CO}$ uptake by brain mito-

Table III. Recovery of Brain Metabolites after CO Hypoxia

\begin{tabular}{lcccc}
\hline $\begin{array}{l}\text { Group No. } \\
\text { Time }\end{array}$ & $\begin{array}{c}3(1.0 \mathrm{ATA}) \\
45\end{array}$ & $\begin{array}{c}4(1.0 \mathrm{ATA}) \\
90\end{array}$ & $\begin{array}{c}5(2.5 \mathrm{ATA}) \\
45\end{array}$ & $\begin{array}{c}6(2.5 \mathrm{ATA}) \\
90\end{array}$ \\
\hline \multicolumn{1}{c}{$\min$} & & & & \\
$n$ & 6 & 7 & 7 & 8 \\
$\mathrm{MAP}$ & $131 \pm 7$ & $119 \pm 8$ & $136 \pm 13$ & $139 \pm 8$ \\
$\mathrm{Hb}$ & $12.5 \pm 0.5$ & $11.2 \pm 0.4$ & $12.1 \pm 0.7$ & $12.3 \pm 0.2$ \\
$\mathrm{CaO}_{2}$ & $16.7 \pm 0.7$ & $15.8 \pm 0.5$ & $16.7 \pm 1.2$ & $15.1 \pm 0.3$ \\
$\mathrm{HbCO}^{\prime}$ & $9.1 \pm 0.6$ & $4.3 \pm 0.2$ & $5.8 \pm 0.3$ & $3.8 \pm 0.3$ \\
$\mathrm{PaO}_{2}$ & $305 \pm 19$ & $298 \pm 15$ & $296 \pm 58$ & $273 \pm 24$ \\
$\mathrm{PaCO}_{2}$ & $39.0 \pm 3.8$ & $41.3 \pm 4.2$ & $32.0 \pm 6.7$ & $38.7 \pm 2.3$ \\
pHa & $7.39 \pm 0.04$ & $7.30 \pm 0.02$ & $7.38 \pm 0.07$ & $7.35 \pm 0.03$ \\
$\mathrm{ATP}$ & $2.21 \pm 0.16$ & $2.49 \pm 0.08$ & $2.78 \pm 0.21$ & $2.65 \pm 0.31$ \\
$\mathrm{ADP}$ & $0.59 \pm 0.03^{*}$ & $0.31 \pm 0.05$ & $0.47 \pm 0.03$ & $0.54 \pm 0.03$ \\
$\mathrm{PCr}$ & $0.72 \pm 0.11^{*}$ & $2.98 \pm 0.20$ & $3.11 \pm 0.31$ & $2.67 \pm 0.31$ \\
$\mathrm{Cr}$ & $8.46 \pm 0.16^{*}$ & $4.64 \pm 0.62$ & $7.06 \pm 0.28^{*}$ & $6.70 \pm 0.31$ \\
Succinate & $2.36 \pm 0.18^{*}$ & $0.46 \pm 0.17$ & $0.69 \pm 0.21$ & $0.91 \pm 0.21$ \\
Glucose & $3.57 \pm 0.24$ & $1.83 \pm 0.17$ & $2.67 \pm 0.36$ & $2.19 \pm 0.24$ \\
Lactate & $1.42 \pm 0.16$ & $1.92 \pm 0.82$ & $1.89 \pm 0.20$ & $1.58 \pm 0.20$ \\
Pyruvate & $0.11 \pm 0.01$ & $0.11 \pm 0.02$ & $0.11 \pm 0.02$ & $0.11 \pm .01$ \\
L/P & $13.3 \pm 0.9$ & $16.6 \pm 4.6^{*}$ & $20.9 \pm 3.4^{*}$ & $14.5 \pm 1.0$ \\
& & & &
\end{tabular}

Abbreviations as defined in Table II. * Values that are significantly different from control values (see Table II). Metabolite concentrations expressed as micromoles per gram wet weight. 
chondria in the pathogenesis of energy failure during CO hypoxia also is supported by the three major findings of this study. First, the spectral data indicate incomplete recovery of the mitochondrial oxidation state in the brain after $\mathrm{CO}$ hypoxia. The oxidation state of cytochrome oxidase after $\mathrm{CO}$ hypoxia could be improved by the administration of hyperbaric pressures of $\mathrm{O}_{2}$. This improvement was associated with spectral evidence of dissolution of the cytochrome $a_{3}-\mathrm{CO}$ ligand in the brain cortex. Second, the progressive depletion of the $\mathrm{PCr}$ reserve after $\mathrm{CO}$ exposure suggests that the incomplete recovery of the cytochrome redox state is an important factor limiting the rate of restoration of aerobic energy metabolism in the rat brain after $\mathrm{CO}$ hypoxia. Finally, the pHi calculations provide evidence of prolonged cerebral intracellular acidosis after $\mathrm{CO}$ hypoxia, which was most pronounced after $\mathrm{HbCO}$ had exerted its maximal effect on $\mathrm{O}_{2}$ transport to the brain. This process, too, was ameliorated by the administration of higher $\mathrm{O}_{2}$ concentrations.

In the brain, analysis of energy-related metabolites is influenced by technical variables (e.g., underestimation of $\mathrm{PCr}$ concentration due to its breakdown during sampling and preparation of the tissue), and by the inability of pooled analysis to distinguish free from bound fraction of metabolites, e.g., ADP. Similar considerations apply to the estimation of $\mathrm{pHi}$ from the CPK reaction. The method used here to harvest brain cortex for bioenergetic profiles, however, has been studied under carefully controlled conditions and found to provide optimal and consistent levels of the energy metabolites suitable for studies of cerebral hypoxia $(19-21,24)$. Also, the CO-related changes in the concentrations of the metabolites detected in this study were reversed more easily at the higher $\mathrm{O}_{2}$ concentration. A notable exception was the concentration of lactate in the brain which remained elevated after $\mathrm{CO}$ exposure, despite $\mathrm{O}_{2}$ treatment. This finding may reflect ongoing glycolysis, a low rate of oxidation of lactate after the injury due to persistent mitochondrial dysfunction (26), or decreased clearance of lactate from the brain, perhaps related to $\mathrm{O}_{2}$-induced vasoconstriction. The possibility of ongoing glycolysis at high $\mathrm{PO}_{2}$ after $\mathrm{CO}$ implies loss of the Pasteur effect, which has been shown to be sensitive to inhibition by $\mathrm{CO}$ in some tissues (27).

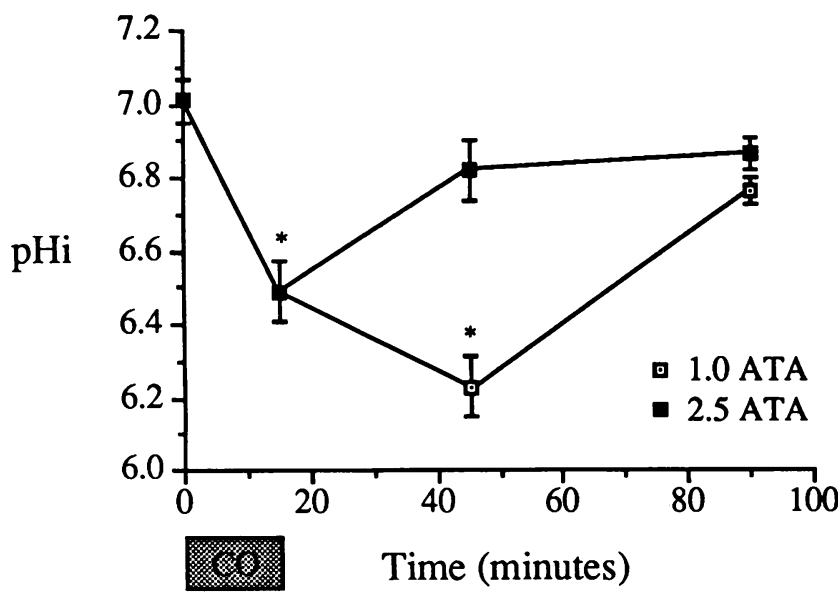

Figure 3. Response of intracellular $\mathrm{pH}(\mathrm{pHi})$ to $\mathrm{CO}$ hypoxia and recovery in rat brain cortex. Values for $\mathrm{pHi}$ were calculated from the phosphocreatine equilibrium and represent mean \pm SEM for $n=6-10$ animals. *Significant differences in $\mathrm{pHi}$ relative to the control value $(P<0.05)$.
We have considered the counter hypothesis that $\mathrm{O}_{2}$-related differences in the rate of restoration of cerebral $\mathrm{O}_{2}$ delivery explain the differences in metabolic recovery after $\mathrm{CO}$ hypoxia. Although more rapid clearance of $\mathrm{HbCO}$ from the blood and greater delivery of dissolved $\mathrm{O}_{2}$ occurred at the higher $\mathrm{Po}_{2}$, the $\mathrm{O}_{2}$ delivery hypothesis is unconvincing for several reasons. The concentration of $\mathrm{HbCO}$ declined rapidly in both treatment groups and was $10 \%$ or less after $45 \mathrm{~min}$ of reoxygenation. In theory, both $\mathrm{O}_{2}$ treatment groups should have improved, as did the hypoxemic animals, if the mechanism of injury was simply tissue hypoxia. Instead, the animals treated at 2.5 ATA improved, while the group treated at 1.0 ATA continued to deteriorate (e.g., decrease in PCr concentration), consistent with inadequate aerobic provision of energy. The measured increase in succinate after $45 \mathrm{~min}$ of recovery in the 1.0 ATA-treated group is quite interesting in this respect because succinate serves as an FAD-linked substrate for mitochondrial complex II, and its concentration is exquisitely sensitive to changes in mitochondrial $\mathrm{O}_{2}$ utilization (28). These biochemical findings cannot be ascribed to differences in the rate at which cerebral $\mathrm{O}_{2}$ delivery was restored, because the difference in arterial $\mathrm{O}_{2}$ content, which amounted to $\sim 50 \%$ at the onset of treatment, should have been compensated for by maintenance of higher cerebral blood flow in animals with the lower $\mathrm{PO}_{2}$ and slower rate of clearance of $\mathrm{HbCO}$. This premise is based on the finding that arterial blood pressure remained well above the autoregulatory threshold for the rat brain throughout the recovery period, and on very good evidence indicating that the hypoxic brain sustains its blood flow response until the metabolic deficit begins to recover (3). This interpretation of the cerebrovascular hemodynamic response could be confirmed experimentally with appropriate measurements of cerebral $\mathrm{O}_{2}$ delivery and metabolic rate during recovery from $\mathrm{CO}$ hypoxia at various $\mathrm{O}_{2}$ concentrations.

In summary, CO-related changes in brain metabolite profiles, delayed recovery of mitochondrial oxidation state after $\mathrm{CO}$ hypoxia and the salutary effects of high partial pressures of inspired $\mathrm{O}_{2}$ on the recovery of cerebral energetics, and $\mathrm{pHi}$ support the concept that $\mathrm{CO}$ can directly inhibit cerebral oxidative metabolism in vivo. This effect of $\mathrm{CO}$ is associated with a surplus of reducing equivalents and an intracellular acidosis which reflect energy imbalance, and could predispose to reoxygenation injury of brain mitochondria and ultimately to energy failure in the cell after $\mathrm{CO}$ poisoning.

\section{Acknowledgments}

The authors thank Craig Marshall and Lynn Tatro for excellent technical assistance and Louise Wilson for preparing the manuscript.

This work was supported by National Institutes of Health grant P01-HL-42444-01-A2 to C. A. Piantadosi.

\section{References}

1. Coburn, R. F., and H. J. Forman. 1987. Carbon monoxide toxicity. Handb. Physiol. (The Respiratory System. Gas Exchange. 3) 4:439-456.

2. Roughton, F. J. W., and R. C. Darling. 1944. The effect of carbon monoxide on the oxyhemoglobin dissociation curve. Am. J. Physiol. 141:17-31.

3. Koehler, R. C., M. D. Jones, and R. J. Traystman. 1982. Cerebral circulatory responses to carbon monoxide and hypoxic hypoxia in the lamb. Am. J. Physiol. 243:H27-H32.

4. Haldane, J. B. S. 1927. Carbon monoxide as a tissue poison. Biochem. J. 21:1068-1075. 
5. Coburn, R. F., and L. B. Mayers. 1971. Myoglobin $\mathrm{O}_{2}$ tension determined from measurements of carboxymyoglobin in skeletal muscle. Am. J. Physiol. 220:66-74.

6. Brown, S. D., and C. A. Piantadosi. 1990. In vivo binding of carbon monoxide to cytochrome c oxidase in rat brain. J. Appl. Physiol. 68:604-610.

7. Jöbsis, F. F. 1974. Intracellular metabolism of oxygen. Am. Rev. Respir. Dis. 110:53.

8. Yoshikawa, S., and W. S. Caughey. 1982. Heart cytochrome $c$ oxidase: an infrared study of effects of oxidation state on carbon monoxide binding. J. Biol. Chem. 257:412-420.

9. Chance, B., M. Erecinska, and M. Wagner. 1970. Mitochondrial responses to carbon monoxide toxicity. Ann. NY. Acad. Sci. 174:193-204.

10. Young, L. J., and W.S. Caughey. 1990. Pathobiochemistry of CO poisoning. FEBS (Fed. Eur. Biochem. Soc.) Lett. 272:1-6.

11. Chance, B. 1951. Rapid and sensitive spectrophotometry. III. A double beam apparatus. Rev. Sci. Instrum. 22:634-638.

12. Jöbsis, F. F., J. H. Keizer, J. C. LaManna, and M. Rosenthal. 1977. Reflectance spectrophotometry of cytochrome a, $\mathrm{a}_{3}$ in vivo. J. Appl. Physiol. Respir. Environ. Exercise Physiol. 43:858-872.

13. Piantadosi, C. A., and F. F. Jöbsis-Vandervliet. 1984. Spectrophotometry of cerebral cytochrome $a, a_{3}$ in bloodless rats. Brain Res. 305:89-94.

14. Piantadosi, C. A., A. L. Sylvia, and F. F. Jöbsis. 1983. Cyanide-induced cytochrome $\mathrm{a}, \mathrm{a}_{3}$ oxidation-reduction responses in rat brain in vivo. J. Clin. Invest. 72:1224-1233.

15. Yonetani, T. 1960. Studies on cytochrome oxidase. I. Absolute and difference absorption spectra. J. Biol. Chem. 235:845-852.

16. Tamura, M., N. Oshino, B. Chance, and I. A. Silver. 1978. Optical measurements of intracellular oxygen concentration of rat heart in vivo. Arch. Biochem. Biophys. 191:8-22.

17. Van Assendelft, O. W. 1970. Light absorption spectra of hemoglobin deviations. In Spectrophotometry of Hemoglobin Derivatives. Royal Vangorcum, The Netherlands 47-72.

18. Piantadosi, C. A., P. A. Lee, and A. L. Sylvia. 1988. Direct effects of CO on cerebral energy metabolism in bloodless rats. J. Appl. Physiol. 65:878-887.

19. Ponten, U., R. A. Ratcheson, L. G. Salford, and B. K. Siesjo. 1973. Optimal freezing conditions for cerebral metabolites in rats. J. Neurochem. 21:11271138 .

20. Folbergrova, J., V. MacMillan, and B. K. Siesjo. 1972. The effect of hypercapnia acidosis upon some glycolytic and Kreb's cycle associated intermediates in the rat brain. J. Neurochem. 19:2507-2517.

21. Lowry, O. H., and J. V. Passoneau. 1972. A Flexible System of Enzymatic Analysis. Academic Press, New York. 291 pp.

22. Bergmeyer, H. U. 1985. In Tri and Dicarboxylic Acids, Purines, Pyrimidines and Derivatives, Coenzymes, Inorganic Compounds. Metabolites 2. 3rd ed. In Methods of Enzymatic Analysis. VCH Verlagsgesellschaft, Wirnheim, Germany. 7:25-33.

23. Veech, R. L., J. W. R. Lawson, N. W. Cornell, and H. A. Krebs. 1979. Cytosolic phosphorylation potential. J. Biol. Chem. 254:6538-6547.

24. MacMillan, V. 1975. The effects of acute carbon monoxide intoxication on the cerebral energy metabolism of the rat. Can. J. Physiol. Pharmacol. 53:354362.

25. Kreisman, N. R., T. J. Sick, J. C. LaManna, and M. Rosenthal. 1981. Local tissue oxygen tension-cytochrome $a, a_{3}$ redox relationships in rat cerebral cortex in vivo. Brain Res. 218:161-174.

26. Siesjo, B. K. 1978. Ischemia. In Brain Energy Metabolism. John Wiley and Sons, New York. 453-526.

27. Laser, H. 1937. Tissue metabolism under the influence of carbon monoxide. Biochem. J. 31:1677-1682.

28. Grieshaber, M. K., U. Kreutzer, and H. O. Portner. Critical $\mathrm{PO}_{2}$ of euryoxic animals. In Oxygen Sensing in Tissues. H. Acker, editor. Springer-Verlag, New York. 37-48. 